\title{
Could Commercial Credit Alleviate the Financing Constraints of SMEs?
}

\author{
Yangqing $\mathrm{Xiao}^{\mathrm{a}, *}$, Yinping $\mathrm{He}$ \\ Finance and Economics College, Jimei University, Xiamen, Fujian Province, China \\ axyq@xmu.edu.cn \\ *Corresponding author: Yangqing Xiao
}

Keywords: small and medium-sized enterprises; financing constraints; commercial credit

\begin{abstract}
Based on the data of listed small and medium enterprises in China from 2007 to 2016, this paper uses Euler equation model and GMM method to analyze the financing constraints faced by SMEs and the role of commercial credit in easing financing constraints. The results show that financing constraints do exist in SMEs and cannot be eased by commercial credit. Therefore, small and medium enterprises need to find other ways to solve the financing problem.
\end{abstract}

\section{Introduction}

Small and medium enterprises are the main driving force of China's economic development, but they are usually suffered by financing difficulties. As early as 1980s, Steven Fazzari and his colleagues put forward the financing constraint hypothesis. [1] In reality, the size of Chinese enterprises is inversely proportional to the amount of loans they received (World Bank Investment Environment Survey of 2003); the financing constraints faced by private enterprises are even more serious. [2] [3] [4]

At present, the financial system of China is dominated by large, state-owned banks. It is this structural mismatch that makes SMEs unable to meet their capital needs from the banking system. [5] For this reason, enterprises have to turn to suppliers which are closely related to their business for commercial credit. Could commercial credit alleviate the financing constraints of SMEs? There is no consistent conclusion in existing literature. Some scholars hold that commercial credit can relieve financing constraints to a large extent. [6] [7] [8] Researchers hold opposing views mainly include Jie Zhang and Dong Liu, [9] as well as Xiao-ping Xu and her colleagues. [10] However, Zheng-fei Lu and De-ming Yang believe that whether commercial credit can solve the financing problem of SMEs depends on the monetary policy environment. [11] We believe that the main reason for above diversified views lies in the different quantitative indicators of commercial credit. Former scholars choose accounts receivable, while latter scholars use accounts payable in their research. In fact, SMEs are both demanders and suppliers of commercial credits. This paper argues that the net commercial credit (accounts payable minus accounts receivable) obtained by SMEs is a more appropriate indicator which can measure the commercial credit obtained by SMEs more accurately and analyze the impacts of commercial credit on SMEs' financing constraints. In terms of model selection, this paper adopts the LOVE (2003) Euler equation to study the relationship between business credit and SMEs' financing constraints, which varies greatly from the investment-cash flow model and cash-cash flow model in existing literature. The rest of this paper is planned as following: the second part is the research hypothesis and model selection; the third part is the empirical results and robustness test; the fourth part is the summary and suggestions.

\section{Research Hypothesis and Model Selection.}

As risk-averse financial institutions, banks tend to issue loans to companies with considerable amount of mortgage assets and well-groomed audited financial statements. Small and medium-sized enterprises are suffered with greater risks because of their unstable operation and opaque accounts; 
the lacking of mortgage makes banks even more unwilling to provide financial supports. Based on above analysis, following assumptions are put forward.

Hypothesis 1: financing constraints of SMEs do exist.

Small and medium-sized enterprises need to buy raw materials from suppliers. If the supplier is a large enterprise, it may require the small enterprise to pay in advance. However, the products produced by the small company may be sold to another big enterprise which adopts delayed payment. This kind of situation leads to the fund shortage of small and medium-sized enterprises. It can be seen that in market competition, SMEs are in unfavorable positions. The market pressure may force them to provide other enterprises with commercial credits more than they have obtained, and become the net provider of commercial credits. Therefore, commercial credit aggravates the financing constraints of SMEs, rather than alleviate them. Based on above analysis, the second hypothesis is put forward.

Hypothesis 2: commercial credit cannot alleviate the financing constraints of SMEs.

Based on Love (2003) Euler equation, this paper uses investment-cash flow sensitivity to analyze whether SMEs have financing constraints and whether commercial credit can ease the financing constraints of SMEs. The mechanism of investment-cash flow sensitivity is: if SMEs have financing constraints, there will be a positive relationship between cash flow and investment. That is, if the cash flow held by an enterprise increased in previous period, the investment of that enterprise would also increase at this period: the coefficient of investment-cash flow sensitivity should be positive. Otherwise, The sensitivity coefficient of investment cash flow will be negative, indicating that enterprises do not have financing constraints. In model (1), in order to verify whether SMEs have financing constraints, the researcher mainly investigates the sign of $\beta 4$, the coefficient of investment cash flow sensitivity. If $\beta_{4}$ is greater than zero, the financing constraints of SMEs do exist. In order to test whether commercial credit can alleviate the financing constraints of SMEs, the product of cash flow and commercial credit is introduced into the Euler equation of model (1). In model (2), the researcher mainly investigates the sign of $\beta_{5}$. If commercial credit can alleviate the financing constraints of SMEs to a certain extent, the dependence of SMEs' investment on internal cash flow will reduce; $\beta 5$ will be less than zero. Otherwise, $\beta_{5}$ will be greater than zero.

$$
\begin{aligned}
& \left(\frac{\mathrm{I}}{\mathrm{K}}\right)_{\mathrm{i}, \mathrm{t}}=\beta_{0}+\beta_{1}\left(\frac{\mathrm{I}}{\mathrm{K}}\right)_{\mathrm{i}, \mathrm{t}-1}+\beta_{2}\left(\frac{\mathrm{I}}{\mathrm{K}}\right)_{\mathrm{i}, \mathrm{t}-1}^{2}+\beta_{3}\left(\frac{\mathrm{V}}{\mathrm{K}}\right)_{\mathrm{i}, \mathrm{t}-1}+\beta_{4}\left(\frac{\mathrm{CF}}{\mathrm{K}}\right)_{\mathrm{i}, \mathrm{t}-1}+\varepsilon_{\mathrm{i}, \mathrm{t}} \\
& \left(\frac{\mathrm{I}}{\mathrm{K}}\right)_{\mathrm{i}, \mathrm{t}}=\beta_{0}+\beta_{1}\left(\frac{\mathrm{I}}{\mathrm{K}}\right)_{\mathrm{i}, \mathrm{t}-1}+\beta_{2}\left(\frac{\mathrm{I}}{\mathrm{K}}\right)_{\mathrm{i}, \mathrm{t}-1}^{2}+\beta_{3}\left(\frac{\mathrm{V}}{\mathrm{K}}\right)_{\mathrm{i}, \mathrm{t}-1}+\beta_{4}\left(\frac{\mathrm{CF}}{\mathrm{K}}\right)_{\mathrm{i}, \mathrm{t}-1}+\beta_{5}\left(\frac{\mathrm{CF}}{\mathrm{K}}\right)_{\mathrm{i}, \mathrm{t}-1} \times \mathrm{TC}_{\mathrm{i}}+\varepsilon_{\mathrm{i}, \mathrm{t}}
\end{aligned}
$$

In model (1) and model (2), I represents the investment of SMEs; Y represents the output of SMEs; CF represents the cash flow of SMEs; K represents the capital on stock of SMEs; TC represents the net commercial credit [(accounts payable - accounts receivable) / total assets] obtained by SMEs; $\varepsilon$ is a random disturbance; i represents the enterprise; $t$ represents time.

Data in this paper comes from CSMAR database. All research samples are small and medium-sized listed companies come from the manufacturing industry of China. The sample range is from 2007 to 2016. After excluding * ST, ST, PT companies and companies without complete data, 780 sets of panel data are obtained from 78 companies.

\section{Empirical Results and Robustness Test}

\subsection{Descriptive statistics.}

The researcher focuses on the statistical description of net business credit of SMEs (Table 1). The mean value of net commercial credits of SMEs is less than zero, indicating most SMEs need to provide more commercial credits than they obtained. In the process of collecting and processing data, it is also found that most enterprises have more accounts receivable than accounts payable. Therefore, it is estimated that the coefficient in model (2) will be greater than zero, representing that commercial credit cannot alleviate the financing constraints of SMEs. At the same time, the standard deviation of 
TC is 0.114 . The relatively big value indicates that net commercial credits vary greatly by enterprises.

Table 1. Descriptive statistics of major variables

\begin{tabular}{llllll}
\hline & observed data & Mean value & $\begin{array}{l}\text { standard } \\
\text { deviation }\end{array}$ & maximum & minimum \\
\hline $\mathrm{I} / \mathrm{K}$ & 780 & 0.091 & 0.091 & 1.276 & 0.001 \\
$\mathrm{Y} / \mathrm{K}$ & 780 & 0.893 & 0.811 & 8.383 & 0.083 \\
$\mathrm{CF} / \mathrm{K}$ & 780 & 0.070 & 0.093 & 0.472 & -0.189 \\
$\mathrm{TC}$ & 780 & -0.055 & 0.114 & 0.340 & -1.599 \\
\hline
\end{tabular}

\subsection{Empirical result analysis.}

The explanatory variable of Euler equation model selected in this paper contains time-delay terms of explained variable; the hypothesis of strictly exogenous of the explanatory variable is certainly not tenable. Thus, this paper uses the first-order difference GMM method to estimate the model and solve the endogenous problem. The researcher firstly estimates model (1) to test whether SMEs have financing constraints. Then, the product item of cash flow and business credit is introduced into model (2) for estimation. The estimated results are shown in table 2.

Table 2. Results of model test

\begin{tabular}{|c|c|c|c|c|c|c|}
\hline & \multicolumn{3}{|c|}{ First-order difference GMM } & \multicolumn{3}{|c|}{ Systematic GMM } \\
\hline & (1) & (2) & (3) & (4) & (5) & (6) \\
\hline$(\mathrm{I} / \mathrm{K})_{\mathrm{t}-1}$ & $\begin{array}{c}0.467 * * * \\
(4.29)\end{array}$ & $\begin{array}{c}0.455^{* * *} \\
(4.36)\end{array}$ & $\begin{array}{c}0.491 * * * \\
(4.93)\end{array}$ & $\begin{array}{c}0.514 * * * \\
(4.83)\end{array}$ & $\begin{array}{c}0.507 * * * \\
(4.20)\end{array}$ & $\begin{array}{c}0.523 * * * \\
(4.20)\end{array}$ \\
\hline$(\mathrm{I} / \mathrm{K}) 2 \mathrm{t}-1$ & $\begin{array}{c}-0.357 * * * \\
(-5.15)\end{array}$ & $\begin{array}{c}-0.425 * * * \\
(-3.92)\end{array}$ & $\begin{array}{c}-0.355^{* * * *} \\
(-4.46)\end{array}$ & $\begin{array}{c}-0.304 * * * \\
(-3.72)\end{array}$ & $\begin{array}{c}-0.342 * * * \\
(-3.34)\end{array}$ & $\begin{array}{c}-0.289 * * * \\
(-3.39)\end{array}$ \\
\hline$(\mathrm{Y} / \mathrm{K})_{\mathrm{t}-1}$ & $\begin{array}{r}0.004 \\
(036)\end{array}$ & $\begin{array}{l}0.013 \\
(0.94)\end{array}$ & $\begin{array}{c}0.001 \\
(-0.04)\end{array}$ & $\begin{array}{c}-0.018^{*} \\
(-1.82)\end{array}$ & $\begin{array}{l}-0.007 \\
(-0.98)\end{array}$ & $\begin{array}{l}-0.016 \\
(-1.47)\end{array}$ \\
\hline$(\mathrm{CF} / \mathrm{K})_{\mathrm{t}-1}$ & $0.207 * *$ & $0.337 * * *$ & $0.291^{* *}$ & $0.229 * *$ & $0.195^{* *}$ & $0.121 *$ \\
\hline$(\mathrm{CF} / \mathrm{K})_{\mathrm{t}-1} \times \mathrm{TC}_{\mathrm{t}-1}$ & $(2.05)$ & $\begin{array}{c}(2.60) \\
0.443^{*} \\
(2.07)\end{array}$ & $(2.36)$ & $(2.37)$ & $\begin{array}{c}(2.19) \\
0.199 * \\
(1.81)\end{array}$ & $(1.71)$ \\
\hline$(\mathrm{CF} / \mathrm{K})_{\mathrm{t}-1} \times \mathrm{TC}_{\mathrm{t}}$ & & & $\begin{array}{c}2.300 * * * \\
(2.69)\end{array}$ & & & $\begin{array}{l}0.337 \\
(0.51)\end{array}$ \\
\hline cons & $\begin{array}{c}0.023^{* *} \\
(2.06)\end{array}$ & $\begin{array}{l}0.009 \\
(0.53)\end{array}$ & $\begin{array}{c}0.027 * * \\
(2.13)\end{array}$ & $\begin{array}{c}0.039 * * * \\
(4.17)\end{array}$ & $\begin{array}{c}0.034 * * * \\
(4.08)\end{array}$ & $\begin{array}{c}0.044^{* * * *} \\
(6.20)\end{array}$ \\
\hline sample size & 624 & 624 & 624 & 702 & 702 & 702 \\
\hline number of variables & 63 & 64 & 64 & 87 & 107 & 113 \\
\hline $\operatorname{AR}(1)$ & 0.0002 & 0.0000 & 0.0007 & 0.0001 & 0.0001 & 0.0001 \\
\hline $\operatorname{AR}(2)$ & 0.5734 & 0.5055 & $0 . .5679$ & 0.8218 & 0.9535 & 0.8979 \\
\hline Sargan test $\mathrm{P}$ value & 0.2210 & 0.2706 & 0.3561 & 0.6559 & 0.9721 & 0.9912 \\
\hline
\end{tabular}

Note: $* * * * * *$ respectively indicates significance at the level of $10 \%, 5 \%$ and $1 \%$; the value of $\mathrm{Z}$ is shown within brackets

From data in column (1), Table 2 , it can be seen that there is a significant positive correlation $\left(\beta_{4}=\right.$ $0.207>0$ ) between the amounts of SMEs' investment in this period and their cash flows in previous period, indicating that the investment of SMEs is highly sensitive to internal cash flow. For the same company, if the cash flow of the previous period increases by 1\%, its investment in this period will increases by $0.207 \%$. The relationship shows that financing constraints of SMEs do exist. From column (1) we can also find that enterprise's investment in this period is significantly positively correlated to its investment in previous period, and negatively correlated with the square of its front-end investment, which shows that enterprises' investment in this period is affected by its previous investment. Generally speaking, there should be a positive correlation between the income and investment of a company. If its early income increases, the enterprise's current investment will 
also increase. Though the coefficients shown in column (1) of Table 2 are positive, the correlation is not significant. One possible reason is that, sample enterprises in this paper are small and medium-sized enterprises. After paying daily expenses and dividends, only a small part of business income can be left for these companies. So the positive correlation between income and investment is not significant. In the second and third columns of Table 2, we can find that the coefficients of products of cash flow and commercial credit are significantly positive, indicating that commercial credits cannot reduce the dependence of SMEs on internal cash flows. That is to say, commercial credit does not alleviate the financing constraints of SMEs, but aggravates the sensitivity of their investment on internal cash flow to a certain extent. This result conforms with our previous expectations and other scholars' conclusions. One possible reason is that SMEs are not only the demanders of commercial credit; they are also the suppliers of commercial credit. But they do not have enough powers when negotiate with large enterprises because of their weak positions in the market. Therefore, when dealing with upstream and downstream enterprises, many small and medium-sized enterprises have to offer more commercial credits in order to increase sales volume, and gradually become the providers of commercial credit. Thus, commercial credit aggravates the financing problem faced by small and medium-sized enterprises.

\subsection{Robustness test.}

In order to test the robustness of the empirical result, this paper employs the systematic GMM method to conduct a re-empirical analysis. The results are listed in Table 2 . The fourth, fifth and sixth column of Table 2 are the empirical results of the systematic GMM method. From the data it can be found that the coefficient before CF is still greater than zero, indicating that SMEs have financing constraints. The coefficient of product of CF and TC is also greater than zero, indicating that commercial credit cannot ease the financing constraints of SMEs. Therefore, the results obtained by systematic GMM method are basically the same with the results obtained from the first-order difference GMM method, representing that the empirical results are robust. By comparing the results of first-order difference GMM analysis and systematic GMM analysis, we can find that the first-order difference GMM is more effective in this experiment.

\section{Conclusions and Suggestions}

The empirical study in this paper shows that at this stage, commercial credit does not provide SMEs with an effective financing channel; small and medium enterprises need to find other feasible ways. The financing constraints of SMEs come from both internal and external factors. Internal factors include short credit records, the lack of mortgage assets and the missing of complete financial statements; it is difficult for SMEs to address these issues in short term. Therefore, the external financing environment should be improved to alleviate the financing constraints of SMEs. First, the authority should vigorously promote the development of small and medium-sized financial institutions. Small and medium-sized financial institutions have a comparative advantage in lending to SMEs, [12] but their service quantity and quality should be further improved. Second, the supply chain finance should be vigorously promoted. Supply chain finance can alleviate the financing constraints of SMEs efficiently. [13] The state can encourage banks to design and develop more supply chain financial products. Third, the venture capital industry should be vigorously promoted. With their professional visions and experiences, venture capital entrepreneurs can identify SMEs with potentials and market competitiveness, and cultivate them into successful enterprises. [14]

\section{Acknowledgement}

Fund Project: This paper is supported by Foundation for Research Projects of the Education Department of Fujian Province (Project No.: JAS14172) and Foundation for Shangda Research Projects of Jimei University (Project No.: SD201507). 


\section{References}

[1] S.M. Fazzari, R. G. Hubbard, B. C. Petersen, A. S. Blinder, J. M. Poterba, Financing constraints and corporate investment, J. Brookings Papers on Economic Activity. 1 (1988) 141-206.

[2] G. Neil, S. Tenev, D.M. Wagle, China's Emerging Private Enterprises: Prospects for the New Century, International Finance Corporation, Washington, 2000.

[3] H.B. Cheng, L. Yu, Z.L. Xu, Capital structure, credit constraints and credit discrimination: a case study of non-state-owned SMEs in Shanghai, J. The Journal of World Economy. 8 (2005) 67-72.

[4] H.L. Guo, X.P. Xu, Analysis on factors which influence the financing constraints of SMEs, J. South China Journal of Economics. 12 (2012) 36-48.

[5] Y.J. Yao, G.F. Dong, The development of small and medium-sized banks and the financing constraints of small and medium-sized enterprises: an empirical study from the theoretical perspective of optimal financial structure in new economic structures, J. Journal of Finance and Economics. 40 (2014) 105-114.

[6] X.J. Shi, S.M. Zhang, Commercial credit, financing constraints and efficiency effects, J. Economic Research Journal. 1 (2010) 102-114.

[7] W.R. Liu, W.J. Sheng, Does commercial credit supplements the banking credit system? J. The Journal of World Economy. 11 (2011) 103-120.

[8] F.Y. Sun, F.Y. Li, L.J. Gu, Could commercial credit provide an effective financing channel for enterprises: analysis from the perspective of investment, J. Economics (Quarterly). 13 (2014) 56-71.

[9] J. Zhang, C.Y. Jing, D. Liu, Commercial credit, relational lending and small business credit constraints: evidence from Jiangsu, J. The Journal of World Economy. 3 (2007) 75-85.

[10] X.P. Xu, M. Li, Provision of commercial credit: evidence from SMEs in Shanghai, J. Journal of Financial Research. 6 (2009) 161-174.

[11] Z.F. Lu, D.M. Yang, Business credit: financing alternative or buyer's market? J. Management World. 4 (2011) 6-45.

[12] Y.F. Lin, X.F. Sun, Y. Jiang, A preliminary study on the theory of optimal financial structure in economic development, J. Economic Research Journal. 8 (2009) 4-17.

[13] W.B. Zhang, K. Liu, Can supply chain finance reduce the financing constraints of SMEs? An empirical analysis based on small and medium sized listed companies, J. Economic Science. 3 (2012)108-118.

[14] P. A. Gompers, J. Lerner, M. M. Blair, T. Hellmann, What drives venture capital fundraising? Brookings Papers on Economic Activity Microeconomics. 1 (1998) 149-204. 